\title{
Cardiovascular Risk Factors (CVrf) in Rural and Urban Areas Mali: Data from the Step 2013 Survey
}

\section{Hamidou Oumar Bâ ${ }^{*}$, Ichaka Menta1, Youssouf Camara², Ibrahima Sangaré1, Guida Landouré ${ }^{3}$, Georges Rosario Christian Millogo ${ }^{4}$, Souleymane Coulibaly ${ }^{3}$, Ilo Bella Diall ${ }^{3}$}

\author{
${ }^{1}$ CHU Gabriel Touré Bamako, Bamako, Mali \\ ${ }^{2} \mathrm{CHU}$ Kati, Bamako, Mali \\ ${ }^{3} \mathrm{CHU}$ Point G, Bamako, Mali \\ ${ }^{4} \mathrm{CHU}$ YO-Ouagadougou, Ouagadougou, Burkina-Faso \\ Email: ^bhamiba@yahoo.fr
}

How to cite this paper: Bâ, H.O., Menta, I., Camara, Y., Sangaré, I., Landouré, G., Millogo, G.R.C., Coulibaly, S. and Diall, I.B. (2018) Cardiovascular Risk Factors (CVrf) in Rural and Urban Areas Mali: Data from the Step 2013 Survey. World Journal of Cardiovascular Diseases, 8, 35-47. https://doi.org/10.4236/wjcd.2018.81005

Received: December 15, 2017 Accepted: January 16, 2018

Published: January 19, 2018

Copyright $(9) 2018$ by authors and Scientific Research Publishing Inc. This work is licensed under the Creative Commons Attribution International License (CC BY 4.0).

http://creativecommons.org/licenses/by/4.0/

\begin{abstract}
Background: Traditional cardiovascular risk factors (CVrf) like hypertension, diabetes, dyslipidemia, obesity, smoking have been studied extensively through theses in hospital studies. Therefore, recent published data from community based studies are rare in Mali. Available data are old justifying to perform a community based study on traditional CVrf in rural and urban areas. Materials and Methods: We retrospectively performed a study which data stemmed from the last STEPS survey carried out in 2013 in some rural and urban areas of Mali. We studied hypertension, diabetes, tobacco smoking, obesity based on body mass index, waist circumference and waist-to-hip ratio. After bivariates analyses, we conducted a logistic regression with rural/urban as dependent variable using SPSS as analysis software for this purpose. Results: Weight, height, WC and HC were higher in urban area with $69.77 \mathrm{Kg}$, $169.13 \mathrm{~cm}, 85.98 \mathrm{~cm}$ and $97.26 \mathrm{~cm}$ compared to $66.27,165.42,81.46$ and 93.23 in rural area $(p<0.001)$. We had more female in rural area and educational level was higher in urban area. In bivariate analysis obesity based on BMI, WC, alcohol consumption was more prevalent in urban area while elevated waist-to-hip ratio was more prevalent in rural area. But in logistic regression for female, the Odds for Tobacco smoking rural as reference was 0.334 [CI: $0.151-0.738$ ] $(p=0.007)$ and that for WHr is 0.582 [CI: $0.415-0.815$ ] $(p<$ $0.001)$. The OR for Obesity based on waist circumference was 2.698 [CI: 1.881 - 3.871] $(p<0.001)$. Rural male as reference diabetes was the only risk factor which became statistically significant with OR of (OR 0.579 and CI [0.346$0.971], p=0.038)$. Conclusion: Traditional cardiovascular risk factors have
\end{abstract}


high prevalence in this study and need to be monitored with larger studies.

Female predictors were raised waist circumference in favour of urban and tobacco smoking and waist-to-hip ratio in favour of urban dwellers. Male diabetes was the only predictor we found.

\section{Keywords}

Cardiovascular Risk Factor, Rural, Urban, Community, Mali

\section{Introduction}

Cardiovascular risk factors (CVrf) have been established for several decades and are becoming increasingly prevalent with a significant amount of data in the world and in Africa [1]-[6]. Classically, some of them are called unmodifiable, others as behavioral [7]. In Mali, traditional CVrf like hypertension, diabetes, dyslipidemia, obesity, smoking have been studied extensively in hospital studies for theses, but few data have been published [8] [9] [10]. In addition, data from extra-hospital population studies are rare or old [11] [12]. There is therefore a need to update the data beyond the usual administrative reports provided by the Department of Health. We therefore carried out this study to study the traditional CVrf in rural and urban areas.

\section{Materials and Methods}

We conducted a cross sectional population-based study, which data stemmed from the 2013 STEPS survey in urban and rural areas. This approach has been described by the World Health Organization (WHO) [13].

\section{Sampling and data collection}

The study sample is based on the last STEPS-Survey which was conducted in 2013 with 2102 subjects aged from 15 to 65 years of whom 1543 (73.4\%) lived in urban and $559(26.6 \%)$ in rural areas.

It was conducted in administrative units known as "Communes" and within each commune in towns/villages.

A two stage cluster sampling method was used to select subjects from urban and rural areas. First clusters were obtained among "Communes" in the three involved regions and second clusters from "Quartiers" within these "Communes". Households were then randomly selected and all eligible adults in the household were interviewed, underwent physical exam and measurements were taken.

The sample size was calculated using the formula:

$$
n=Z^{2} p q / i^{2} \times d
$$

with $n=$ sample size, $Z=1.96, p=40 \%=0.40, q=1-p=0.6, i=3 \%=0.03, d=$ 2.

A total of 30 Clusters as given bellow were obtained: 


\begin{tabular}{cccl}
\hline Commune & Number of clusters & Type of area & \multicolumn{1}{c}{ Quartiers/villages } \\
\hline II (Bamako) & 3 & Urban & Bakaribougou, Médinacoura; Niarela \\
III (Bamako) & 3 & Urban & Bamakocourabolibana, Dravelila, N’Tomicorobougou \\
VI (Bamako) & 6 & Urban & Banankabougou, Magnanbougou, Missabougou, Niamakoro, Sogoniko; Yirimadjo \\
Koulikoro & 5 & Urban & Katibougou, Kasso, Kolebougou, Koulikoroba, Koulikorogarre I \\
Kati central & 3 & Rural & Kati coura, Malibougou, Sébénicoro \\
Ouélessébougou & 2 & Rural & Fanicodiana, Tinkele \\
Ségou & 4 & Urban & Bagadadji, Darsalam, Mission, Sidosonicoura \\
Sikasso & 4 & Urban & Boula hameau, Lafiabougoukoko, Quartuier résidentiel, Wayerma I \\
Total & 30 & & \\
\hline
\end{tabular}

\section{Data collection:}

Following data were recorded for each study participant:

- Sociodemographic characteristics,

- 3 blood pressures and heart rate measures in 5 min interval, using their mean as systolic, diastolic blood pressure respectively SBP, DBP and heart rate (HR)

- Fasting/postprandial glycemia,

- Weight in kilogram $(\mathrm{Kg})$, height in centimeter $(\mathrm{cm})$ allowing to calculated body mass index $(\mathrm{BMI})$ in $\mathrm{Kg} / \mathrm{m}^{2}$ as Weight $(\mathrm{Kg})$ divided by Height $(\mathrm{cm})$ squared.

- Waist circumference (WC), Hip Circumference (HC) all in $\mathrm{cm}$

- ratio Waist-to-Hip (rWH) as WC in $\mathrm{cm}$ divided by $\mathrm{HC}$ in $\mathrm{cm}$

Teams of three medical staff personal were built and trained to use the survey formulary and to perform measurements during household visit (and second visit in case household members were not present). Each subject was interviewed and from him different measures were obtained according to guidelines of the WHO STEPS approach for chronic disease surveillance [13].

Interviews were performed by medical personal and focused on socio-demographic characteristics, lifestyle, cardiovascular risk factors, personal and family history of cardio-vascular diseases or other chronic illnesses.

Height was measured without shoes to the nearest centimeter with subject stand on the footplate with back against stadiometer rule.

Weight was measured to the nearest $0.1 \mathrm{~kg}$ on an electronic scale with the subject wearing light clothing and no shoes.

Waist circumference (WC) and Hip circumference (HC) was measured with a stretch-resistant tape that is wrapped snugly around the subject, but not constricting.

WC was measured at the midpoint between the lower border of the rib cage and the iliac crest with the subject being light clothed.

HC was measured around the widest portion of the buttocks.

We used for blood pressure measurements an apparatus with a medium and large cuff size and performed measures at rest, the subject in sitting position on the right arm. The mean of the two blood pressure readings was used for each 
subject in this study. A third measure was performed in some cases if blood pressure values were borderline.

\section{Definitions}

Education level was graded as followed:

- Level 0: no school attending

- Level 1: school attending for 1 - 6

- Level 2: school attending for 7 - 9

- Level 3: school attending for 10 - 12

- Level 4: school attending for 12 and more years

Hypertension was defined as systolic blood pressure (SBP) $\geq 140 \mathrm{mmHg}$ and/or diastolic blood pressure (DBP) $\geq 90 \mathrm{mmHg}$ or self-reported use of antihypertensive drug irrespective of measured blood pressure [14].

Mean arterial blood pressure (mBP) was calculated with this formula:

$$
\mathrm{DBP}+((\mathrm{SBP}-\mathrm{DBP}) / 3)
$$

General obesity was defined by body mass index (BMI) and further central obesity through the waist circumference (WC) [15] [16].

BMI served to define weight disorders as following:

- Underweight (UW): $<18.5$

- Normal weight (NW): $\geq 18.5$ and $<24.99$

- Overweight (OW): $\geq 25.00$ and $<29.99$

- Obesity (OB): $\geq 30.00$

Based on waist circumference, OW was defined as $W C \geq 90 \mathrm{~cm}$ and $\geq 80$ respectively for men and women and central $\mathrm{OB}$ as waist $\geq 102 \mathrm{~cm}$ for men and $\geq 88 \mathrm{~cm}$ for women [16].

For the ratio Waist-to-Hip (rWH) Men with a rWH $0.90-0.99$ and women with a rWH $0.80-0.84$ were classified as overweight, while men with a $\mathrm{rWH} \geq$ 1.00 and women with a rWH $\geq 0.85$ were classified as obese [16].

Diabetes was assessed with a glucometer (one-touch ultra Bayer'), fasten or postprandial with cutting values of resp 1.26 and $2 \mathrm{~g}$ or the use of antidiabetic medicine.

\section{Data analysis:}

Sociodemographic data and continues variables were described and the results presented in tables with statistical tests $\left(\mathrm{Chi}^{2}\right.$ or Fisher dependent of your applicability).

Then we carried out a logistic regression analysis with setting (rural or urban) as dependent factor. We then used for this analysis potential predictors age, sex, education level, obesity based on BMI, WC, rWH, smoking, alcohol consumption, HTN and diabetes.

References for the logistic regression were age group $<30 \mathrm{y}$, education level $\leq$ 9, No smoking, No alcohol consumption, No HTN, No Diabetes and normal weight for BMI, WC and rWH. p-value $<0.05$ was considered statistically significant.

The SPSS software version 20 was used for data analysis. 


\section{Results}

\section{Description of variables}

Means for quantitative variables are presented in Table 1. Weight, height, WC and HC showed statistically significant differences. These four parameters were all higher in urban area with $69.77 \mathrm{Kg}, 169.13 \mathrm{~cm}, 85.98 \mathrm{~cm}$ and $97.26 \mathrm{~cm}$ compared to $66.27,165.42,81.46$ and 93.23 in rural area $(p<0.001)$. The other continuous variables did not differ significantly.

Among the socio-demographic characteristics, gender and educational level differed significantly. There was more female in rural area and educational level was higher in urban area (Table 2).

Obesity based on BMI and WC circumference was higher in urban areas with $16.20 \%$ and $31.20 \%$ compared to $9.20 \%$ and $21.60 \%$ in rural areas $(p<0.001)$.

rWH-based obesity was higher in rural areas with $50.80 \%$ versus $44.20 \%$ in urban $(p=0.009)$ (Table 2).

Alcohol consumption was more prevalent with $6.7 \%$ in urban area against $3.7 \%$ in rural $(p=0.009)$ (Table 2).

Apart from smoking and hypertension, prevalence for cardiovascular risk factors increased up to 59 years and regressed after (Diagram 1).

From all CVrf obesity (based on BMI, WC and rWH) was more common in female sex with the highest value for obesity based on rWH (Diagram 2).

Tobacco smoking had an almost ten times higher prevalence in male sex (24.4\%) versus $2.7 \%$ in female sex (Diagram 2 ).

Prevalence for Hypertension was $25.4 \%$ in male sex and $22.8 \%$ in female sex (Diagram 2).

Table 1. Description of continues variables in rural and urban setting.

\begin{tabular}{|c|c|c|c|c|c|c|c|c|c|c|}
\hline \multirow{2}{*}{ Variables } & \multicolumn{3}{|c|}{ Rural } & \multicolumn{3}{|c|}{ Urban } & \multicolumn{3}{|c|}{ Total } & \multirow{2}{*}{$p$} \\
\hline & Moy. & $\mathbf{N}$ & $\mathrm{SD}$ & Moy. & $\mathbf{N}$ & SD & Moy. & $\mathbf{N}$ & SD & \\
\hline Age & 37.27 & 559 & 14.696 & 36.60 & 1543 & 15.425 & 36.78 & 2102 & 15.234 & 0.373 \\
\hline Weight (Kg) & 66.27 & 549 & 13.102 & 69.77 & 1515 & 15.453 & 68.84 & 2064 & 14.941 & $<0.001$ \\
\hline Height $(\mathrm{cm})$ & 165.42 & 556 & 10.960 & 169.13 & 1516 & 10.711 & 168.14 & 2072 & 10.901 & $<0.001$ \\
\hline $\mathrm{BMI}\left(\mathrm{Kg} / \mathrm{m}^{2}\right)$ & 24.17 & 546 & 4.303 & 24.51 & 1501 & 5.591 & 24.42 & 2047 & 5.280 & 0.203 \\
\hline $\mathrm{WC}(\mathrm{cm})$ & 81.46 & 527 & 14.869 & 85.98 & 1456 & 15.053 & 84.78 & 1983 & 15.133 & $<0.001$ \\
\hline $\mathrm{HC}(\mathrm{cm})$ & 93.23 & 534 & 19.137 & 97.26 & 1353 & 14.589 & 96.12 & 1887 & 16.105 & $<0.001$ \\
\hline WHr & 0.89 & 514 & 0.122 & 0.89 & 1308 & 0.108 & 0.89 & 1822 & 0.112 & 0.670 \\
\hline SBP (mmHg) & 120.29 & 559 & 22.628 & 119.31 & 1525 & 27.534 & 119.57 & 2084 & 26.306 & 0.450 \\
\hline DBP (mmHg) & 77.46 & 559 & 13.175 & 76.49 & 1525 & 16.619 & 76.75 & 2084 & 15.772 & 0.212 \\
\hline $\mathrm{HR}(/ \mathrm{min})$ & 74.41 & 559 & 16.109 & 73.57 & 1532 & 17.418 & 73.79 & 2091 & 17.078 & 0.318 \\
\hline Glycemia (g/l) & 110.18 & 555 & 26.327 & 111.67 & 1481 & 44.488 & 111.26 & 2036 & 40.355 & 0.460 \\
\hline
\end{tabular}

SBP: systolic blood pressure, DBP: diastolic blood pressure, HR: heart rate, SD: standard deviation. 


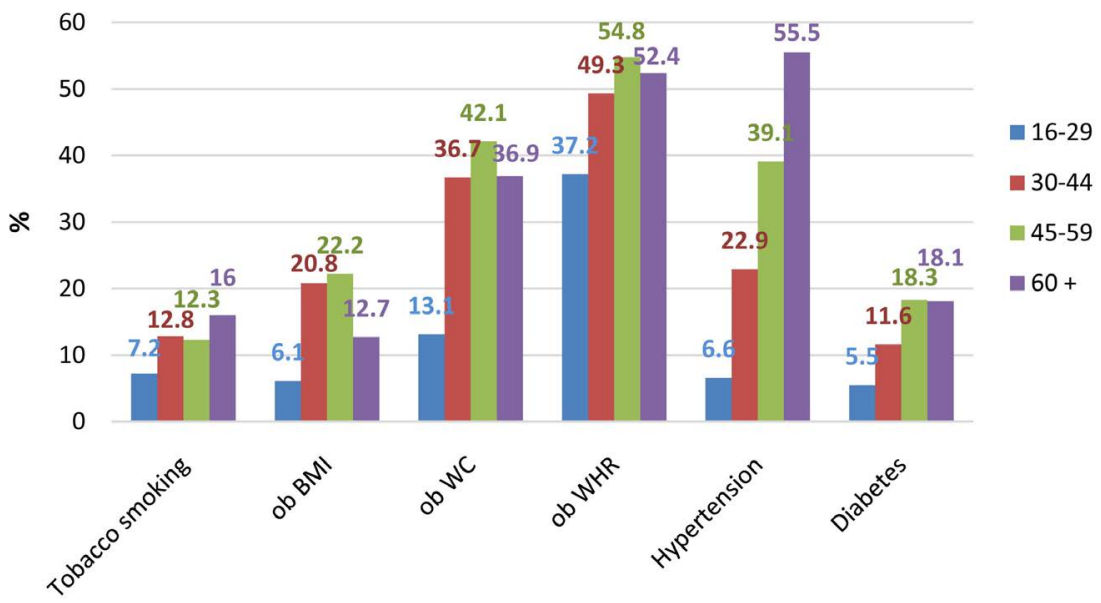

Cardiovascular risk factors

Diagram 1. Cardiovascular risk factors by age group in the 2013 STEP survey in Mali. ob BMI: obesity based on BMI, ob WC: obesity based on waist circumference, ob WHR: obesity based on the ratio waist to hip.

Table 2. Sociodemographic characteristics and CVrf in rural and urban setting in the 2013 STEP survey in Mali.

\begin{tabular}{|c|c|c|c|c|c|c|}
\hline \multirow{2}{*}{ Variables } & & \multicolumn{2}{|c|}{ Setting (\%) } & \multicolumn{2}{|c|}{ Total } & \multirow{2}{*}{$p$} \\
\hline & & Rural & Urban & $\%$ & $\mathbf{N}$ & \\
\hline \multirow{4}{*}{ Age group (years) } & $16-29$ & 36.49 & 41.09 & 39.87 & 838 & 0.114 \\
\hline & $30-44$ & 29.34 & 25.28 & 26.36 & 554 & \\
\hline & $45-59$ & 23.79 & 21.97 & 22.45 & 472 & \\
\hline & $60+$ & 10.38 & 11.67 & 11.32 & 238 & \\
\hline \multirow{3}{*}{ Sex } & Male & 33.27 & 38.63 & 37.20 & 782 & 0.025 \\
\hline & Female & 66.73 & 61.37 & 62.80 & 1320 & \\
\hline & $0-6$ & 62.97 & 52.50 & 55.28 & 1162 & $<0.001$ \\
\hline \multirow{3}{*}{ Education level* } & $7-9$ & 19.14 & 14.39 & 15.65 & 329 & \\
\hline & $10-12$ & 14.31 & 26.38 & 23.17 & 487 & \\
\hline & $\geq 13$ & 3.58 & 6.74 & 5.90 & 124 & \\
\hline \multirow[t]{2}{*}{ Tobacco smoking } & No & 88.60 & 89.40 & 89.20 & 1875 & 0.563 \\
\hline & Yes & 11.40 & 10.60 & 10.80 & 227 & \\
\hline \multirow[t]{2}{*}{ Alcohol consumption } & No & 96.30 & 93.30 & 94.10 & 1814 & 0.012 \\
\hline & Yes & 3.70 & 6.70 & 5.90 & 114 & \\
\hline \multirow[t]{2}{*}{ Obesity BMI } & No & 90.80 & 83.80 & 85.60 & 1754 & $<0.001$ \\
\hline & Yes & 9.20 & 16.20 & 14.40 & 294 & \\
\hline \multirow[t]{2}{*}{ Obesity WC } & No & 78.40 & 68.80 & 71.30 & 1414 & $<0.001$ \\
\hline & Yes & 21.60 & 31.20 & 28.70 & 569 & \\
\hline \multirow[t]{2}{*}{ Obesity rWH } & No & 49.20 & 55.80 & 53.90 & 1002 & 0.009 \\
\hline & Yes & 50.80 & 44.20 & 46.10 & 856 & \\
\hline \multirow[t]{2}{*}{ HTN } & No & 78.90 & 75.30 & 76.20 & 1589 & 0.086 \\
\hline & Yes & 21.10 & 24.70 & 23.80 & 495 & \\
\hline \multirow[t]{2}{*}{ Diabetes } & No & 89.20 & 88.40 & 88.60 & 1860 & 0.582 \\
\hline & Yes & 10.80 & 11.60 & 11.40 & 239 & \\
\hline
\end{tabular}

${ }^{*}$ school attending in years. 


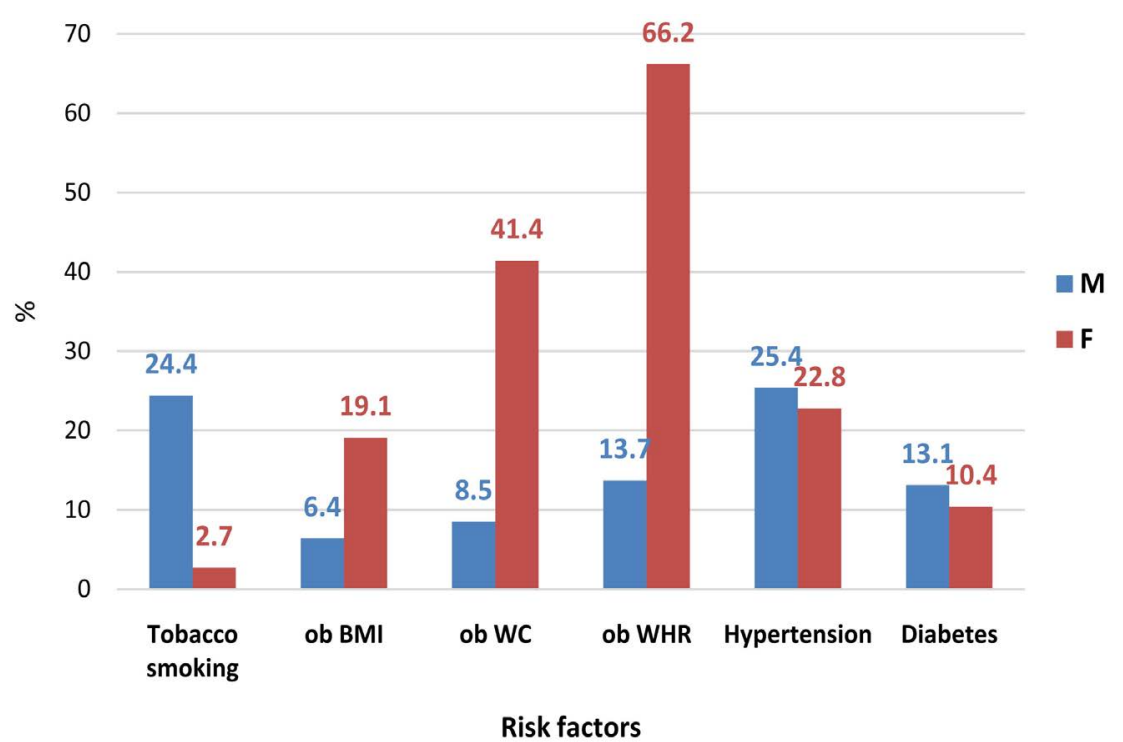

Diagram 2. Cardiovascular risk factors by gender in the 2013 STEP survey in Mali. ob BMI: obesity based on BMI, ob WC: obesity based on waist circumference, ob WHR: obesity based on the ratio waist to hip.

\section{Logistic regression}

The regression analysis was first performed using setting as dependent variable for the entire sample and found sex, education level, obesity based on WC and WHR statistically significant with following odd ratios and confidence intervals: (Table 3):

- Female sex: 0.691 and CI [0.512 - 0.931] $(p=0.015)$

- Education level with $\leq 9$ as reference

10 - 12: 2.172 and CI [1.599 - 2.952] $(p<0.001)$

$12+: 2.211$ and CI [1.287 - 3.797] $(p=0.004)$

- WC with OR of 2.338 and IC [1.689 - 3.237] $(p<0.001)$

- WHR with OR 0.683 and IC [0.517 - 0.904] $(p<0.001)$

Association for age group was significant but not stable.

We further performed logistic regression using always setting as dependent variable for each sex.

For female education level, tobacco smoking, WC-based and WHr-based obesity reached statistically stable significance with following results (Table 4):

- Education level with $\leq 9$ as reference

10 - 12: 2.198 and CI $[1.449-3.335](p<0.001)$

$12+: 5.340$ and CI [1.802 - 15.822] $(p=0.003)$

- Tobacco smoking: 0.334 and IC [0.151 - 0.738] $(p=0.007)$

- WC with OR of 2.698 and IC [1.881 - 3.871] $(p<0.001)$

- WHr with OR 0.582 and IC [0.415 - 0.815] $(p<0.001)$

Same logistic regression procedure performed with men found only diabetes (OR 0.579 and CI [0.346 - 0.971], $p=0.038$ ) statistically significant (Table 5). Association with education level was not stable. 
Table 3. CVrf predictors rural area as reference.

\begin{tabular}{|c|c|c|c|c|c|c|c|c|}
\hline \multirow{2}{*}{ All sample } & \multirow{2}{*}{ B } & \multirow{2}{*}{ S.E. } & \multirow{2}{*}{ Wald } & \multirow{2}{*}{$\mathrm{df}$} & \multirow{2}{*}{$p$} & \multirow{2}{*}{ OR } & \multicolumn{2}{|c|}{$95 \%$ C. I. for OR } \\
\hline & & & & & & & Lower & Upper \\
\hline $\begin{array}{c}\text { Age group in years }<30 \\
\text { as reference }\end{array}$ & & & 8.810 & 3 & 0.032 & & & \\
\hline $30-44$ & -0.422 & 0.151 & 7.828 & 1 & 0.005 & 0.656 & 0.488 & 0.881 \\
\hline $45-59$ & -0.346 & 0.163 & 4.475 & 1 & 0.034 & 0.708 & 0.514 & 0.975 \\
\hline $60+$ & -0.193 & 0.211 & 0.842 & 1 & 0.359 & 0.824 & 0.545 & 1.246 \\
\hline Female sex & -0.370 & 0.153 & 5.885 & 1 & 0.015 & 0.691 & 0.512 & 0.931 \\
\hline $\begin{array}{c}\text { Education level }{ }^{*} \leq 9 \\
\text { as reference }\end{array}$ & & & 29.624 & 2 & 0.000 & & & \\
\hline $10-12$ & 0.776 & 0.156 & 24.588 & 1 & 0.000 & 2.172 & 1.599 & 2.952 \\
\hline $12+$ & 0.793 & 0.276 & 8.266 & 1 & 0.004 & 2.211 & 1.287 & 3.797 \\
\hline Tobacco smoking & -0.337 & 0.191 & 3.121 & 1 & 0.077 & 0.714 & 0.491 & 1.038 \\
\hline Alcohol consumption & 0.233 & 0.286 & 0.659 & 1 & 0.417 & 1.262 & 0.720 & 2.211 \\
\hline Obesity (BMI) & 0.292 & 0.211 & 1.915 & 1 & 0.166 & 1.339 & 0.885 & 2.025 \\
\hline Obesity (WC) & 0.849 & 0.166 & 26.183 & 1 & 0.000 & 2.338 & 1.689 & 3.237 \\
\hline Obesity (rWH) & -0.381 & 0.142 & 7.142 & 1 & 0.008 & 0.683 & 0.517 & 0.904 \\
\hline HTN & 0.187 & 0.147 & 1.613 & 1 & 0.204 & 1.205 & 0.903 & 1.609 \\
\hline Diabetes & -0.126 & 0.183 & 0.478 & 1 & 0.489 & 0.881 & 0.616 & 1.261 \\
\hline
\end{tabular}

*school attending in years.

Table 4. CVrf predictors among women, rural as reference.

\begin{tabular}{|c|c|c|c|c|c|c|c|c|}
\hline \multirow{2}{*}{ Female } & \multirow{2}{*}{ B } & \multirow{2}{*}{ S.E. } & \multirow{2}{*}{ Wald } & \multirow{2}{*}{ df } & \multirow{2}{*}{$p$} & \multirow{2}{*}{ OR } & \multicolumn{2}{|c|}{$95 \%$ C. I. for OR } \\
\hline & & & & & & & Lower & Upper \\
\hline $\begin{array}{c}\text { Age group in years }<30 \\
\text { as reference }\end{array}$ & & & 8.456 & 3 & 0.037 & & & \\
\hline $30-44$ & -0.472 & 0.195 & 5.871 & 1 & 0.015 & 0.624 & 0.426 & 0.914 \\
\hline $45-59$ & -0.477 & 0.207 & 5.295 & 1 & 0.021 & 0.620 & 0.413 & 0.932 \\
\hline $60+$ & -0.102 & 0.284 & 0.131 & 1 & 0.718 & 0.903 & 0.518 & 1.574 \\
\hline $\begin{array}{c}\text { Education level }{ }^{*} \leq 9 \\
\text { as reference }\end{array}$ & & & 21.379 & 2 & 0.000 & & & \\
\hline $10-12$ & 0.788 & 0.213 & 13.712 & 1 & 0.000 & 2.198 & 1.449 & 3.335 \\
\hline $12+$ & 1.675 & 0.554 & 9.139 & 1 & 0.003 & 5.340 & 1.802 & 15.822 \\
\hline Tobacco smoking & -1.097 & 0.405 & 7.349 & 1 & 0.007 & 0.334 & 0.151 & 0.738 \\
\hline Alcohol consumption & 0.388 & 0.638 & 0.369 & 1 & 0.543 & 1.474 & 0.422 & 5.150 \\
\hline Obesity (BMI) & 0.138 & 0.238 & 0.337 & 1 & 0.562 & 1.148 & 0.720 & 1.829 \\
\hline Obesity (WC) & 0.993 & 0.184 & 29.076 & 1 & 0.000 & 2.698 & 1.881 & 3.871 \\
\hline Obesity (rWH) & -0.542 & 0.172 & 9.947 & 1 & 0.002 & 0.582 & 0.415 & 0.815 \\
\hline HTN & 0.096 & 0.188 & 0.261 & 1 & 0.609 & 1.101 & 0.761 & 1.593 \\
\hline Diabetes & 0.255 & 0.261 & 0.953 & 1 & 0.329 & 1.290 & 0.774 & 2.152 \\
\hline
\end{tabular}

*school attending in years. 
Table 5. CVrf predictors among men, rural as reference.

\begin{tabular}{|c|c|c|c|c|c|c|c|c|}
\hline \multirow[b]{2}{*}{ Male } & \multirow[b]{2}{*}{ B } & \multirow{2}{*}{ S.E. } & \multirow{2}{*}{ Wald } & \multirow{2}{*}{$\mathrm{df}$} & \multirow[b]{2}{*}{$p$} & \multirow{2}{*}{ OR } & \multicolumn{2}{|c|}{$95 \%$ C. I. for OR } \\
\hline & & & & & & & Lower & Upper \\
\hline $\begin{array}{c}\text { Age group in years }<30 \\
\text { as reference }\end{array}$ & & & 1.743 & 3 & 0.627 & & & \\
\hline $30-44$ & -0.308 & 0.242 & 1.619 & 1 & 0.203 & 0.735 & 0.457 & 1.181 \\
\hline $45-59$ & -0.074 & 0.273 & 0.073 & 1 & 0.787 & 0.929 & 0.544 & 1.586 \\
\hline $60+$ & -0.089 & 0.327 & 0.074 & 1 & 0.786 & 0.915 & 0.482 & 1.737 \\
\hline $\begin{array}{c}\text { Education level }^{*} \leq 9 \\
\text { as reference }\end{array}$ & & & 9.727 & 2 & 0.008 & & & \\
\hline $10-12$ & 0.719 & 0.235 & 9.375 & 1 & 0.002 & 2.052 & 1.295 & 3.251 \\
\hline $12+$ & 0.401 & 0.334 & 1.439 & 1 & 0.230 & 1.493 & 0.776 & 2.875 \\
\hline Tobacco smoking & -0.118 & 0.223 & 0.277 & 1 & 0.598 & 0.889 & 0.574 & 1.378 \\
\hline Alcohol consumption & 0.098 & 0.326 & 0.090 & 1 & 0.764 & 1.103 & 0.582 & 2.089 \\
\hline Obesity (BMI) & 0.575 & 0.499 & 1.329 & 1 & 0.249 & 1.777 & 0.669 & 4.724 \\
\hline Obesity (WC) & 0.277 & 0.454 & 0.371 & 1 & 0.542 & 1.319 & 0.541 & 3.212 \\
\hline Obesity (rWH) & 0.189 & 0.300 & 0.397 & 1 & 0.528 & 1.208 & 0.671 & 2.175 \\
\hline HTN & 0.316 & 0.245 & 1.667 & 1 & 0.197 & 1.372 & 0.849 & 2.216 \\
\hline Diabetes & -0.546 & 0.264 & 4.283 & 1 & 0.038 & 0.579 & 0.346 & 0.971 \\
\hline
\end{tabular}

*school attending in years.

\section{Discussion}

We conducted a community-based study, the first of its kind on a large sample of urban and rural subjects.

\section{Prevalence}

Tobacco use with a prevalence of $10.80 \%$ is high but still below prevalence in other African countries [17] and in most countries outside Africa [17] [18] [19]. Unlike Chockalingam [20], we found no significant difference between rural and urban. Freeman et al. [21] underlined large reductions in tobacco smoking prevalence from 1980-2012. In that study in supplement data tobacco smoking prevalence seems to be constant around $10 \%$.

Obesity in general was more important in the female sex and in urban areas as found by Ziraba [22], Garcia et al. [23]. Based on the BMI, there was no significant difference in our sample compared to Ziraba [22]. Sartorius [24] emphasized the increasing prevalence of obesity especially in the female sex. This study did not allow us to verify this trend in the Malian population.

Hypertension and diabetes constitute a burden for African countries [25] [26] [27] [28]. According to Mohsen and Damasceno [29], Mali will be in the intermediate prevalence range between $20 \%$ - $30 \%$.

Global diabetes prevalence of $11.4 \%$ is of big concern with near same prevalence in rural and urban setting. This prevalence is higher than those published by Hall et al. [30]. 


\section{Logistic Regression}

Results from the logistic regressions could be interpreted as following:

- In the whole sample only obesity was statistically significant in comparing urban and rural dwellers, with raised waist circumference more prevalent in urban and raised rWH more prevalent in rural area.

- Among female: tobacco smoking was less prevalent in urban setting like in India [20]. But rural urban pattern have been described as inconsistent [30] [31]. WC-based obesity was more than twice and half in urban setting as found in others studies [32] while data are opposed about rural urban pattern in neighbour lands [33]. But generally obesity seems to be more prevalent in urban area [33]. Opposed to WC-based obesity rWH-based obesity was more prevalent in rural area.

- Among male: Diabetes the only risk factor with statistically significant association was more prevalent in rural area. Diabetes pattern in rural and urban areas are variable [34], so that further studies in Mali are necessary to confirm our finding and to further look for differences between rural and urban dwellers if such differences exist.

\section{Strengths and Weaknesses of the Study}

We provided prevalence data on a sample from the general population collected according to the WHO STEP wise approach. Data presented in this form were not available to the best of our knowledge.

Lipids level was not available in this sample primarily for financial constraints. Having that would permit a better calculation of the cardiovascular risk according to most of the standards. Nonetheless we provide first order data which could lead to further studies with more in deep analysis for better planning of strategies against $\mathrm{CV}$ rf.

\section{Conclusion}

Traditional cardiovascular risk factors have high prevalence in this study and need to be monitored with larger studies. Female predictors were raised waist circumference in favour of urban and tobacco smoking and waist-to-hip ratio in favour of urban dwellers. Male diabetes was the only predictor we found.

\section{Acknowledgements}

To Dr. Nazoum Diarra, who led for years the non-communicable disease section at the Ministry of Health for giving us opportunity to publish these data.

\section{References}

[1] Yusuf, S., Reddy, S., Ôunpuu, S. and Anand, S. (2001) Global Burden of Cardiovascular Diseases. Circulation, 104, 2746-2753.

https://doi.org/10.1161/hc4601.099487

[2] Chockalingam, A., Campbell, N.R. and Fodor, J.G. (2006) Worldwide Epidemic of Hypertension. Canadian Journal of Cardiology, 22, 553-555. 
https://doi.org/10.1016/S0828-282X(06)70275-6

[3] (2010) The Emerging Risk Factors Collaboration Diabetes Mellitus, Fasting Blood Glucose Concentration, and Risk of Vascular Disease: A Collaborative Meta-Analysis of 102 Prospective Studies. The Lancet, 375, 2215-2222. https://doi.org/10.1016/S0140-6736(10)60484-9

[4] (2011) The Emerging Risk Factors Collaboration Separate and Combined Associations of Body-Mass Index and Abdominal Adiposity with Cardiovascular Disease: Collaborative Analysis of 58 Prospective Studies. The Lancet, 377, 1085-1095. https://doi.org/10.1016/S0140-6736(11)60105-0

[5] Bloomfield, G.S., Mwangi, A., Chege, P., Simiyu, C.J., Aswa, D.F., Odhiambo, D., Obala, A.A., Ayuo, P. and Khwa-Otsyula, B.O. (2013) Multiple Cardiovascular Risk Factors in Kenya: Evidence from a Health and Demographic Surveillance System Using the WHO STEPwise Approach to Chronic Disease Risk Factor Surveillance. Heart, 99, 1323-1329. https://doi.org/10.1136/heartjnl-2013-303913

[6] Alsheikh-Ali, A.A., Omar, M.I., Raal, F.J., Rashed, W., Hamoui, O., et al. (2014) Cardiovascular Risk Factor Burden in Africa and the Middle East: The Africa Middle East Cardiovascular Epidemiological (ACE) Study. PLoS ONE, 9, e102830. https://doi.org/10.1371/journal.pone.0102830

[7] Payne, R.A. (2012) Cardiovascular Risk. British Journal of clinical Pharmacology, 74, 396-410. https://doi.org/10.1111/j.1365-2125.2012.04219.x

[8] Diarra, M.B., Diarra, A., Sanogo, K.M., Diakité, S., Tchintchui, N., Diall, I.B., Diallo, B.A. and Touré, M.K. (2007) Cardiopathies ischémiques en cardiologie à Bamako (A propos de 162 cas ). Mali Médical, 22, 36-39.

[9] Diallo, B.A. (1994) Profil épidémiologique de l'HTA en milieu hospitalier à Bamako. Médecine d'Afrique Noire, 41, 103-105.

[10] Dembélé, M., Sidibé, A.T., Traoré, H.A., Tchombou, H.I.C., Zounet, B., Traoré, A.K., Diallo, D. and Fongoro, S. (2000) Association HTA-Diabète sucré dans le service de Médecine Interne de l'Hôpital du Point G-Bamako. Médecine d'Afrique Noire, 47, 276-280.

[11] Maiga, M.A., et al. (1989) Epidémiologie de l'hypertension artérielle en zone sahélienne dans le cercle de NARA (Mali). Médecine d' Afrique Noire, 36, 234-237.

[12] Hamidou, O.B., Ichaka, M., Youssouf, C., Ibrahima, S., Noumou, S., Seydou, D. and Mamadou Bocary, D. (2014) Surpoids et obésité dans la population au-dessus de 20 ans en milieu urbain bamakois (Mali). Pan African Medical Journal, 19, 352.

[13] World Health Organisation (2017) L'approche STEPwise de l'OMS pour la surveillance des facteurs de risque des maladies chroniques (STEPS). http://www.who.int/chp/steps

[14] Chobanian, A.V., Bakris, G.L., Black, H.R., Cushman, W.C., Green, L.A., Izzo Jr., J.L., Jones, D.W., Materson, B.J., Oparil, S., Wright Jr., J.T., Roccella, E.J., National Heart, Lung, and Blood Institute Joint National Committee on Prevention, Detection, Evaluation, and Treatment of High Blood Pressure; National High Blood Pressure Education Program Coordinating Committee (2003) The Seventh Report of the Joint National Committee on Prevention, Detection, Evaluation, and Treatment of High Blood Pressure: The JNC 7 Report. JAMA, 289, 2560-2572.

https://doi.org/10.1001/jama.289.19.2560

[15] WHO (2017) Overweight and Obesity. http://www.who.int/entity/mediacentre/factsheets/fs311/en/

[16] WHO (2011) Waist Circumference and Waist-Hip Ratio: Report of a WHO Expert 
Consultation, Geneva, 8-11 December 2008.

http://www.who.int/entity/nutrition/publications/obesity/WHO_report_waistcircu mference_and_waisthip_ratio/en/

[17] Nturibi, E.M., Kolawole, A.A. and McCurdy, S.A. (2009) Smoking Prevalence and Tobacco Control Measures in Kenya, Uganda, the Gambia and Liberia: A Review. International Journal of Tuberculosis and Lung Disease, 13, 165-170.

[18] Li, Z., Zhang, J., Ou, J.X. and Bai, C.X. (2011) Tobacco Smoking in China: Prevalence, Disease Burden, Challenges and Future Strategies. Respirology, 16, 1165-1172. https://doi.org/10.1111/j.1440-1843.2011.02062.x

[19] CDC (2009) State-Specific Prevalence and Trends in Adult Cigarette Smoking-United States, 1998-2007. The Morbidity and Mortality Weekly Report (MMWR), 58, 221-226.

https://www.cdc.gov/mmwr/preview/mmwrhtml/mm5809a1.htm

[20] Chockalingam, K., Vedhachalam, C., Rangasamy, S., Sekar, G., Adinarayanan, S., et al. (2013) Prevalence of Tobacco Use in Urban, Semi Urban and Rural Areas in and around Chennai City, India. PLoS ONE, 8, e76005.

https://doi.org/10.1371/journal.pone.0076005

[21] Ng, M., Freeman, M.K., Fleming, T.D., Robinson, M., Dwyer-Lindgren, L., Thomson, B., Wollum, A., Sanman, E., Wulf, S., Lopez, A.D., Murray, C.J.L. and Gakidou, E. (2014) Smoking Prevalence and Cigarette Consumption in 187 Countries, 1980-2012. JAMA, 311, 183-192. https://doi.org/10.1001/jama.2013.284692

[22] Ziraba, A.K., Fotso, J.C. and Ochako, R. (2009) Overweight and Obesity in Urban Africa: A Problem of the Rich or the Poor? BMC Public Health, 9, 465. https://doi.org/10.1186/1471-2458-9-465

[23] Garcia, M., Mulvagh, S.L., Merz, C.N.B., Buring, J.E. and Manson, J.E. (2016) Cardiovascular Disease in Women: Clinical Perspectives. Circulation Research, 118, 1273-1293. https://doi.org/10.1161/CIRCRESAHA.116.307547

[24] Sartorius, B., Veerman, L.J., Manyema, M., Chola, L. and Hofman, K. (2015) Determinants of Obesity and Associated Population Attributability, South Africa: Empirical Evidence from a National Panel Survey, 2008-2012. PLoS ONE, 10, e0130218. https://doi.org/10.1371/journal.pone.0130218

[25] Adeloye, D. and Basquill, C. (2014) Estimating the Prevalence and Awareness Rates of Hypertension in Africa: A Systematic Analysis. PLoS ONE, 9, e104300. https://doi.org/10.1371/journal.pone.0104300

[26] Sarki, A.M., Nduka, C.U., Strangers, S., Kandala, N.B. and Uthman, O.A. (2015) Prevalence of Hypertension in Low- and Middle-Income Countries: A Systematic Review and Meta-Analysis. Medicine, 94, 1-16. https://doi.org/10.1097/MD.0000000000001959

[27] Gill, G. (2014) Diabetes in Africa-Puzzles and Challenges. Indian Journal of Endocrinology and Metabolism, 18, 249-251. https://doi.org/10.4103/2230-8210.131111

[28] Beran, D., et al. (2006) Diabetes Care in Sub-Saharan Africa. The Lancet, 368, 1689-1695 https://doi.org/10.1016/S0140-6736(06)69704-3

[29] Ibrahim, M.M. and Damasceno, A. (2012) Hypertension in Developing Countries. The Lancet, 308, 611-619. https://doi.org/10.1016/S0140-6736(12)60861-7

[30] Hall, V., Thomsen, R.W., Henriksen, O. and Lohse, N. (2011) Diabetes in Sub Saharan Africa 1999-2011: Epidemiology and Public Health Implications. A Systematic Review. BMC Public Health, 11, 564. 
https://doi.org/10.1186/1471-2458-11-564

[31] Brathwaite, R., Addo, J., Smeeth, L. and Lock, K. (2015) A Systematic Review of Tobacco Smoking Prevalence and Description of Tobacco Control Strategies in Sub-Saharan African Countries; 2007 to 2014. PLOS ONE, 10, e0132401.

https://doi.org/10.1371/journal.pone.0132401

[32] Lissock, C.N.A.A., Sobngwi, E., Ngassam, E. and Ngoa, L.S.E. (2011) Rural and Urban Differences in Metabolic Profiles in a Cameroonian Population. The Pan African Medical Journal, 10, 1. https://doi.org/10.4314/pamj.v10i0.72204

[33] Atek, M., Traissac, P., El Ati, J., et al. (2013) Obesity and Association with Area of Residence, Gender and Socio-Economic Factors in Algerian and Tunisian Adults. PLOS ONE, 8, e75640. https://doi.org/10.1371/journal.pone.0075640

[34] Oyebode, O., Pape, U.J., Laverty, A.A., Lee, J.T., Bhan, N. and Millett, C. (2015) Rural, Urban and Migrant Differences in Non-Communicable Disease Risk-Factors in Middle Income Countries: A Cross-Sectional Study of WHO-SAGE Data. PLoS ONE, 10, e0122747. https://doi.org/10.1371/journal.pone.0122747 